\title{
Comparison of Different Systems of the Stability of Cable-Stayed Bridge
}

\author{
Liu Fangping ${ }^{1}$ \\ ${ }^{1}$ School of Civil Engineering, Chongqing Three Gorges University, Chongqing, China \\ Correspondence: Liu Fangping, School of Civil Engineering, Chongqing Three Gorges University, 780 Erduan \\ Shalong Road, Wanzhou District, Chongqing 404000, China. E-mail: 1fp05270214@163.com
}

Received: December 19, 2013

Accepted: January 13, $2014 \quad$ Online Published: March 11, 2014

doi:10.5539/mas.v8n2p87

URL: http://dx.doi.org/10.5539/mas.v8n2p87

\begin{abstract}
This paper investigates the stability of cable-stayed bridge under three different structural systems. Fengjie Yangtze River Highway Bridge, A large-span prestressed concrete cable-stayed bridge in Chongqing is analyzed by using nonlinear finite element program ANSYS. The buckling mode and linear and nonlinear stability factors of the bridge are gained and compared by numerical simulation of three structural systems: floating, semi-floating and consolidation bridge structural systems, and their buckling mode and stability factors under two unfavorable live loads are compared. The results show: 1) only in-plane instability is induced regardless of the structure system; 2) the floating system is the most instable among the three; 3) Floating system with longitudinal elastic restraint on the main beam is an ideal structural system. This research provides an important theoretical basis for bridge design and construction.
\end{abstract}

Keywords: bridge engineering, Cable-stayed bridge, numerical simulation, Stability response, floating system

\section{Introduction}

According to connection method of towers, girders and piers of the cable-stayed bridge, the floating system, semi-floating system and consolidation systems can be formed. Large-span cable-stayed bridge is different from the conventional. The stability of each system is different under constant load and live load and no one has studied the problem so far as I know. In order to provide important theoretical basis for the design and construction of the bridge, we need to find what kind of large-span prestressed concrete cable-stayed structure system is reasonable (Miao \& Xiao, 2006; Peng \& Zhao, 2011).

\section{Stability Analysis Methodology}

\subsection{The First Stability}

Among the many documents, the view that the first type stability is only to consider the elastic stage of the structures. The following balance equation wrote by the finite element method to express the state of structural instability. In order to consider the geometric nonlinear concepts, stiffness matrix is given by the composition term in the first stability type. By the geometric theory of nonlinear analysis, if structure in the initial configuration of linear equilibrium, whether U.L. formulation or T.L. formulation, its expression is uniform:

$$
\left(\left[K_{0}\right]+\left[K_{\sigma}\right]\right) d\{\delta\}=\left[K_{T}\right] d\{\delta\}=d\{\psi\}
$$

By the definition of first stability issue, we know that when the structure is in critical state, even if the trend of $d\{\psi\}$ zero, $d\{\delta\}$ also has non-zero solution. According to the theory of matrix algebra, there must have the following formula:

$$
\left|\left[K_{0}\right]+\left[K_{\sigma}\right]\right|=0
$$

In the case of small deformation, if a reference load is $\{\bar{\Psi}\}$ (or call initial loading), the corresponding structural geometric stiffness matrix is $\left[\bar{K}_{\sigma}\right]$, critical load is $\{\Psi\}_{c r}=\lambda\left[\bar{K}_{\sigma}\right]$, then, under the action of critical load, geometric stiffness matrix of the structure is:

$$
\left[K_{\sigma}\right]=\lambda\left[\bar{K}_{\sigma}\right]
$$

Put Equation (3) into Equation (2), we can get: 


$$
\left[K_{\sigma}\right]+\lambda\left[\bar{K}_{\sigma}\right]=0
$$

This is the characteristic equation of which to calculate the safety factor. If the equation has n-order, in theory, these must be $n$ Eigen-value as $\lambda_{1}, \lambda_{2}, \cdots, \lambda_{n}$, correspondingly $n$ eigenvectors can be obtained. And they represent the safety factor of stability and the corresponding buckling mode respectively. $\lambda$ called the Eigen-value, also called scale factor or load factor, it is equal to the critical buckling load $\mathrm{P}_{\mathrm{cr}}$ when it multiply the action load $\mathrm{P}$. Action load P can be any function, if it is the unit load, Eigen-value will be the buckling load, if it is the action load, Eigen-value will be the buckling safety factor of the structure (You, He, \& Dong, 2008; Choi, Yoo, Koh, \& Nogami, 2007).

\subsection{The Second Stability}

According to the definition of the extreme point of instability, second structural stability can be understood as the concept of limit load. The concept of ultimate bearing capacity of bridge structure is the bridge to withstand the maximum load capacity of outside. To analyze the ultimate bearing capacity of the bridge, we can see that it not only for its ultimate design, but also to understand the form of destruction in the structure. It tells us exactly the safety margin or over load capacity of the structure under a given load, provides the basis for safety constructions and operational management of the structure.

From the perspective of finite element calculation, the essence of analyzing ultimate bearing capacity of the bridge structure is the process of looking for the ultimate load according to equilibrium equation. In this process, the influence of geometric and material nonlinearity is considered when solving the structural stiffness matrix. Structural stiffness is continuously changing when continuous increasing external loads of the bridge structure. When the compressive stress or shear stress of the external load make the stiffness matrix tend to singular, carrying capacity of the structure would reach the limit, the external load of the structure at this point is the limit load.

The essence of second type stable issue is to solving the load-displacement curve in the entire process of loading of the structure. Generally, to solve the load-displacement curve can be use two ways, one is load increment method, and another is displacement increment method.

\subsubsection{Load Increment Method}

According to U.L formulation, we know from the form of incremental equilibrium equations of the structure, if the $\mathrm{i}$-Level of load increment is $\mathrm{d}\{\Psi\}$ i when the ultimate load loading by stages, there must have the following formula:

$$
\left({ }^{\mathrm{t}}\left[K_{0}\right]+{ }^{\mathrm{t}}\left[K_{\sigma}\right]\right) \mathrm{d}\{\delta\}_{\mathrm{i}}={ }^{\mathrm{t}}\left[K_{T}\right] \mathrm{d}\{\delta\}_{\mathrm{i}}=\mathrm{d}\{\psi\}_{\mathrm{i}}
$$

In formula above, $\mathrm{d}\{\delta\}_{\mathrm{i}}$ is the nodal displacement increment produced by $\mathrm{d}\{\psi\}_{\mathrm{i}}$ in the i-Level loading.

Structural stiffness matrix is a function of displacement. If stiffness is unchanging within each step of load increment, we can get load-displacement curves through a multi-linear fitting. When the load increased to close to the structural instability ultimate load, the whole structure stiffness matrix is singular as a result of the main elements close to zero, at this moment, finite iteration is not converged. We usually consider the ultimate bearing capacity has been achieved at this moment. Of course, the search method can also be used to even more gradually approach the limit load of the structure. Load by load increment method to analyze the stability can only obtain approximate maximum in load-displacement curve, of which have only one ascending. It cannot calculate descending phase. Now, displacement increment method (or displacement control method) can be used. In addition, in ANSYS, arc length method can be used in descending phase of load-displacement curve.

\subsubsection{Displacement Increment Method}

For the general structure, we can route the displacement which we want to control (for example, $u_{2}=\Delta u_{2}$ ) to the last and at the same time block the original stiffness matrix when we rearrange it. The finite element equation becomes:

$$
\left[\begin{array}{ll}
K_{11} & K_{12} \\
K_{21} & K_{22}
\end{array}\right]\left\{\begin{array}{l}
\Delta u_{1} \\
\Delta u_{2}
\end{array}\right\}=\Delta \lambda\left\{\begin{array}{l}
P_{1} \\
P_{2}
\end{array}\right\}+\left\{\begin{array}{l}
R_{1} \\
R_{2}
\end{array}\right\}
$$

In formula above: $\left(\mathrm{P}_{1}, P_{2}\right)^{T}-$ Reference loading vector; $\Delta \lambda$ - Coefficient of the step load; $\left(\mathrm{R}_{1}, R_{2}\right)^{T}-$ the 
imbalance force vector in the process of solving iterative equation; $\left[\begin{array}{l}K_{11}-P_{1} \\ K_{21}-P_{2}\end{array}\right]-$ coefficient matrix.

Rewrite Equation (6) as follow:

$$
\left[\begin{array}{l}
K_{11}-P_{1} \\
K_{21}-P_{2}
\end{array}\right]\left\{\begin{array}{l}
\Delta u_{1} \\
\Delta \lambda
\end{array}\right\}=\left\{\begin{array}{l}
R_{1} \\
R_{2}
\end{array}\right\}-\left[K_{22} K_{12}\right] \Delta u_{2}
$$

Thus, we can control the value of specified $\mathrm{u}_{2}$, find the corresponding $\Delta \mathrm{u}_{1}$ and load increment scale factor $\Delta \lambda$ when solving the equations. Because $K_{\mathrm{ij}}$ related with displacement, it requires iterative calculation when solving, if $\left(\mathrm{R}_{1}, R_{2}\right)^{T}$ value tends to zero, iterative process would convergence.

Displacement increment method can be used effectively to obtain the decline part in load- displacement curve. The coefficient matrix in Equation (7) is asymmetric and zonal, so the larger bandwidth is required for solving. It is one major drawback. Now we define the ratio of the load value before the structure loss carrying capacity to the value of design load is the whole non-linear instability safety factor, that is

$$
\left\{P_{\text {cr }}\right\}=\lambda\left\{P_{\mathrm{sj}}\right\}
$$

In formula above: $\left\{P_{\mathrm{cr}}\right\}$-The total load in the buckling of a certain condition (including dead load and live load);

$\left\{P_{\mathrm{si}}\right\}$ - The design load of a certain condition (including dead load and live load); $\lambda$ - Carry capacity stability safety factor, $\lambda=\lambda_{0}+\lambda_{1}$, among which $\lambda_{0}$ is the basic factor of safety when design load, and it value is one; $\lambda_{1}$ is load factor drawn from the iterative analysis, namely structural safety margin.We can see from above, structural stability and the ultimate bearing capacity of the structure is equivalent. The nonlinear stability analysis and the nonlinear strength analysis of the structure is consistent, they are united in the process of incremental loading. When the load factor $\lambda=\lambda_{0}=1$ in the loading process, nonlinear calculate result is nonlinear deformation and stress state of the structure under the actual loads.

ANSYS can not directly obtain non-linear stability safety factor, that the value $\lambda$ in Equation (7). But it can obtain load-displacement curve through gradual loading. In load-displacement curve, we can determine the instability point of the structure and calculate buckling stability safety factor (Eock, 2011; Tang, 2010).

\section{Numerical Simulation}

\subsection{Project Overview and Finite-Element Modeling}

A bridge over Yangtze River in Chongqing is a large span cable-stayed prestressed concrete bridge with float system. The bridge has a length of 893 meters, main span of 460 meters. Five span using the asymmetric arrangement, that is $30.4+202.6+460+174.7+25.3$ meters, and the bridge width is 20.5 meters. The bridge use the fish bone model to simulate full-bridge beams for spatial analysis. As the force on the side and auxiliary piers very small, we only need to consider the support and constraint role on the main beam. The tower is reinforced concrete rectangular hollow structure, using beam element (beam188 unit) simulating. Main beam model is simplified as fish bone and also use beam element (beam188 unit) simulating. In the finite element model, the member which connects the main beam and the cable named fishbone in the fish bone model is a large rigid rod and use beam element (beam4 unit) simulating. Cable only bears tension, its compressive stiffness is very small, use rod element (link10 unit) simulating. In ANSYS, link10 is the three-dimensional bar unit only for tension or pressure, the unique Characteristic of bilinear stiffness matrix make tensile stiffness disappeared when the cell compressed. The actual state of the bridge is only the tower and pier consolidation, tower and beam is separation, thus, except the main beam is supported by side pier and auxiliary pier, the other supporting are all the cable. The main beam can be a longitudinal floating girder with elastic multi-support, structure system is the floating system. The full-bridge model has a total of 1007 finite element nodes, 832 units. Finite element model shown in Figure 1. 


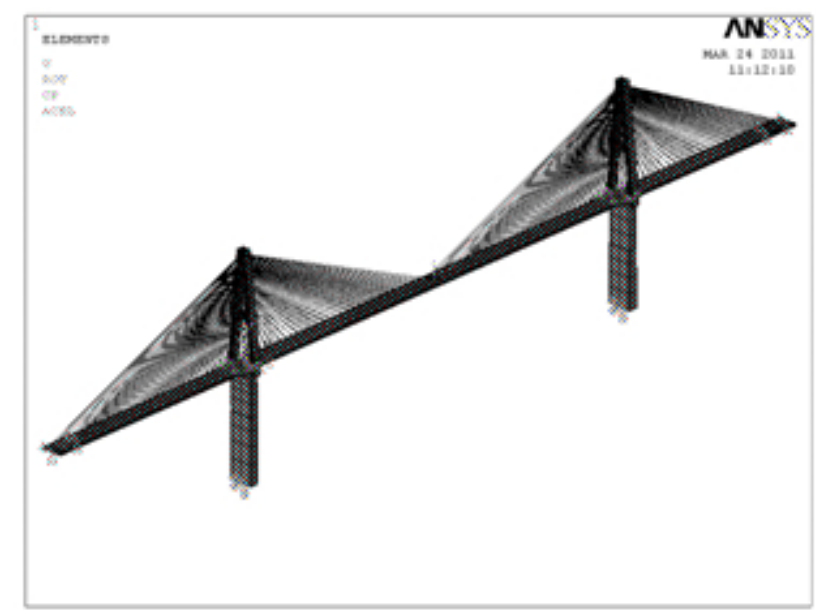

Figure 1. Finite element model of Fengjie Yangtze River highway bridge

\subsection{Different Structural Model}

There is eight thirty meters long longitudinal elastic ropes under the main beam and column intersection to form semi-floating system. If remove them, remain only the tower pier consolidation, tower beam separation, the main longitudinal beams become floatable, the structure will become a floating state. Conversely, if we couple tower bottom, bridge pier and beam the structure becomes consolidation system.

\subsection{The Calculation Result}

When the car load full-bridge arrangement,there are three different structural systems of linear and nonlinear buckling mode shown in Figures 2-4, which left is the linear buckling mode, right is non-linear buckling mode. There are three different curves of nonlinear stability safety factor and control point displacement shown in Figures 5-7. linear and nonlinear stability factor of different situations in Table 1. From them we can concluded that:

Table 1. Linear and nonlinear stability factor of different situations

\begin{tabular}{ccccc}
\hline & Calculation state & load detail & linear value & nonlinear value \\
\hline \multirow{2}{*}{$\begin{array}{c}\text { full-bridge } \\
\text { live load }\end{array}$} & Floating system & dead load, live load, flow force, & 3.06 & 3.04 \\
& Semi-floating system & hit force, wind force, deck paving & 9.84 & 8.11 \\
& consolidation system & deck railing & 10.11 & 9.04 \\
\hline \multirow{2}{*}{$\begin{array}{c}\text { mid-span } \\
\text { live load }\end{array}$} & Floating system & Semi-floating system load, live load, flow force, & 3.15 & 2.86 \\
& consolidation system & hit force, wind force, deck paving & 10.00 & 7.28 \\
& & deck railing & 10.23 & 7.50 \\
\hline
\end{tabular}



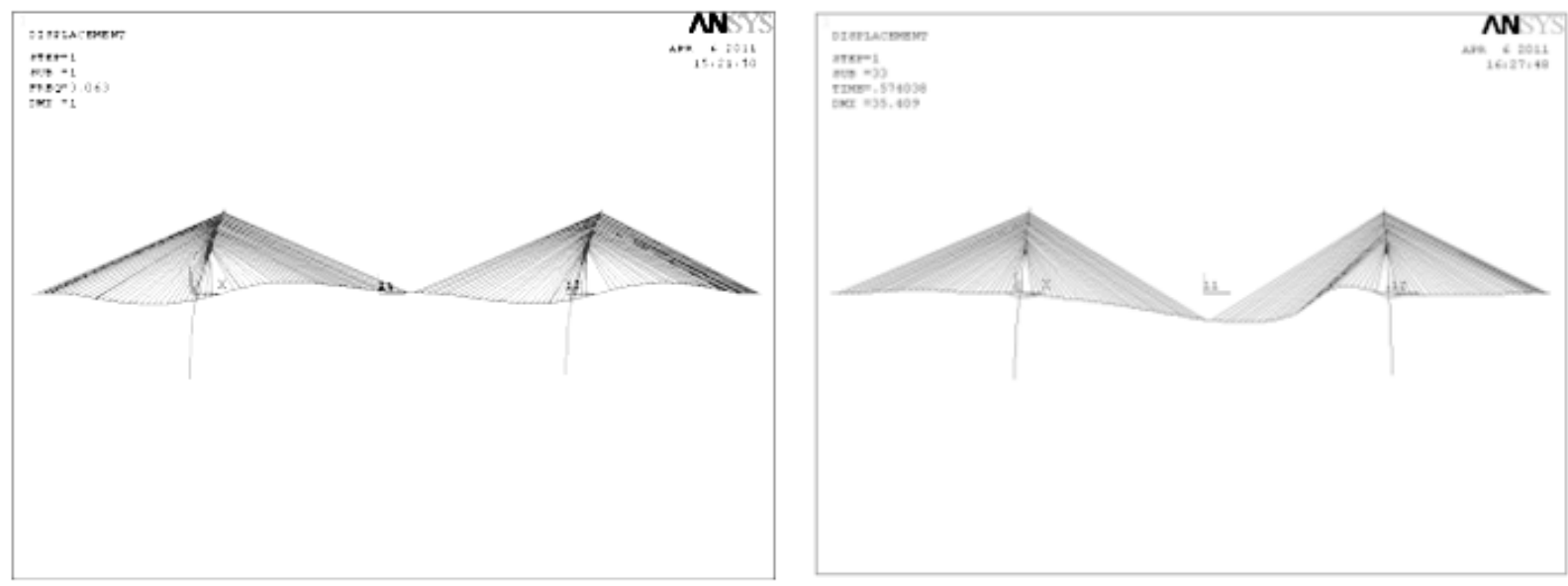

(a) linear buckling model

(b) nonlinear buckling model

Figure 2. First linear and nonlinear buckling model of floating system

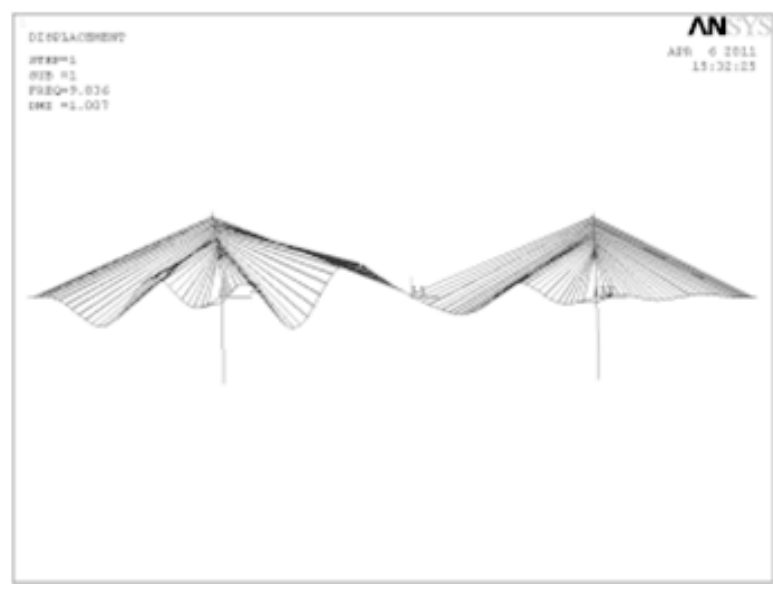

(a) linear buckling model

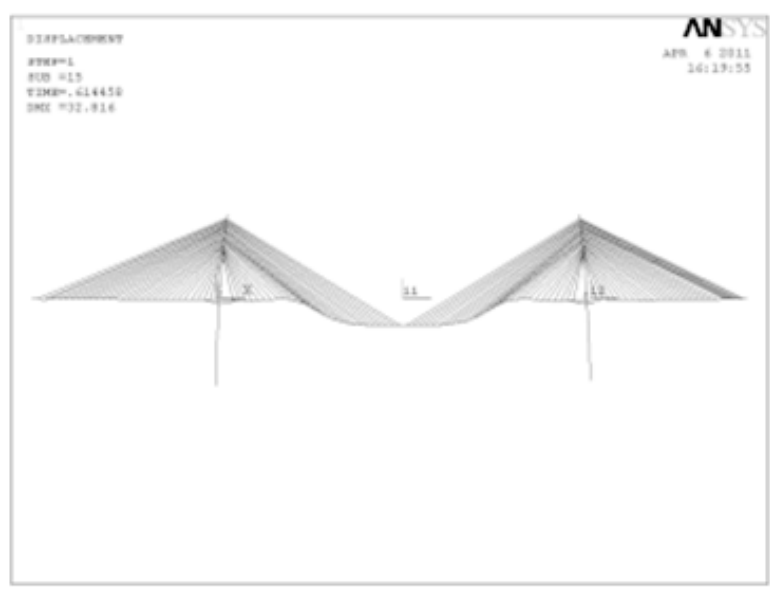

(b) nonlinear buckling model

Figure 3. First linear and nonlinear buckling model of semi-floating system

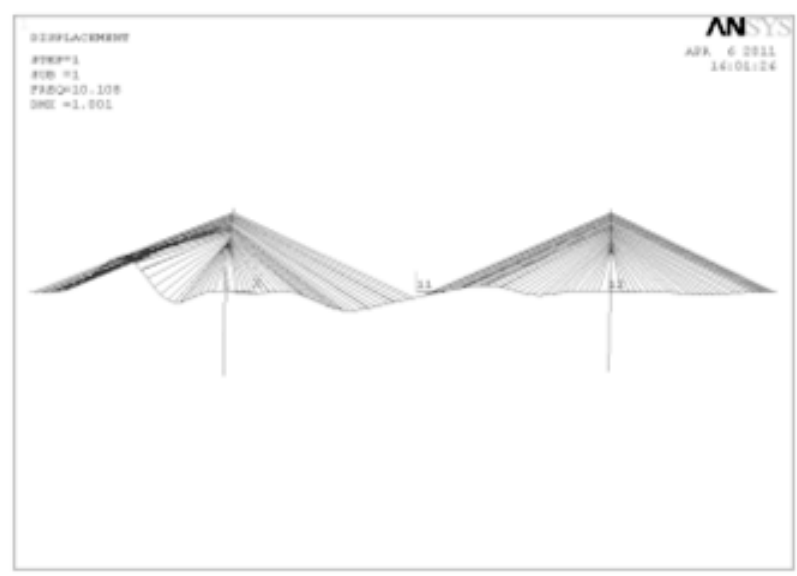

(a) linear buckling model

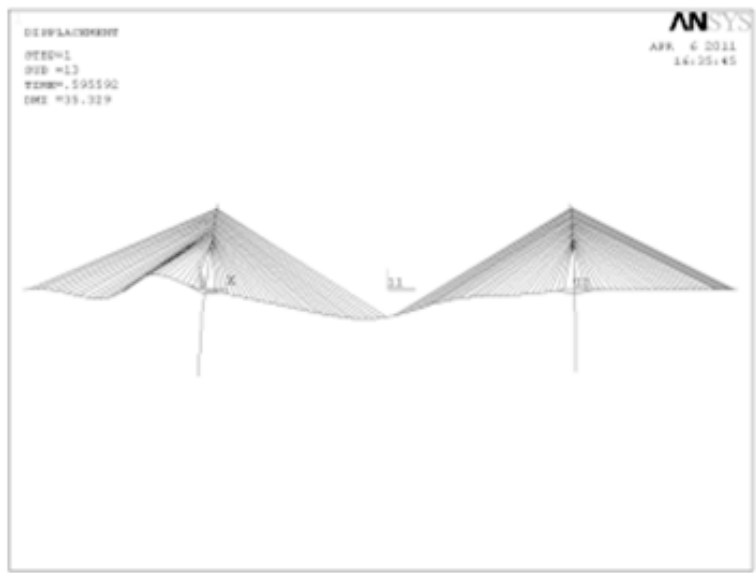

(b) nonlinear buckling model

Figure 4. First linear and nonlinear buckling model of consolidation system 


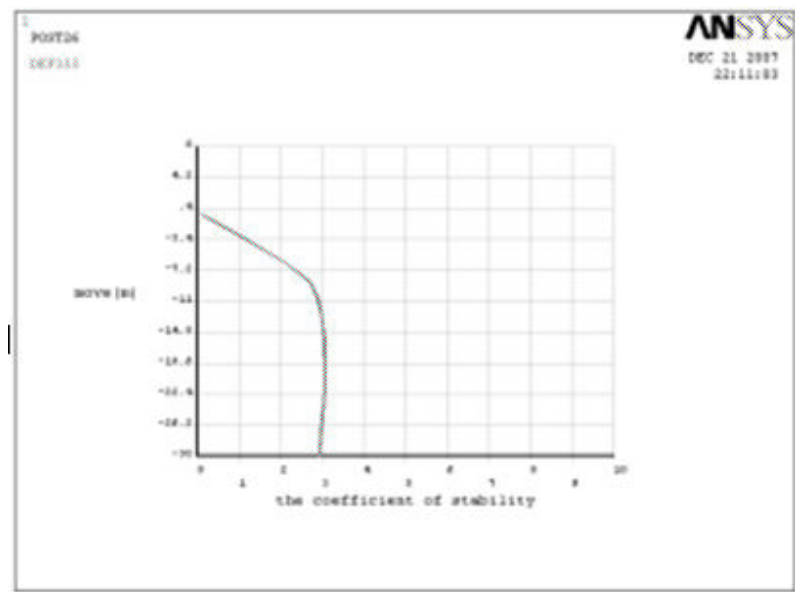

Figure 5 . The factor of stability of floating system

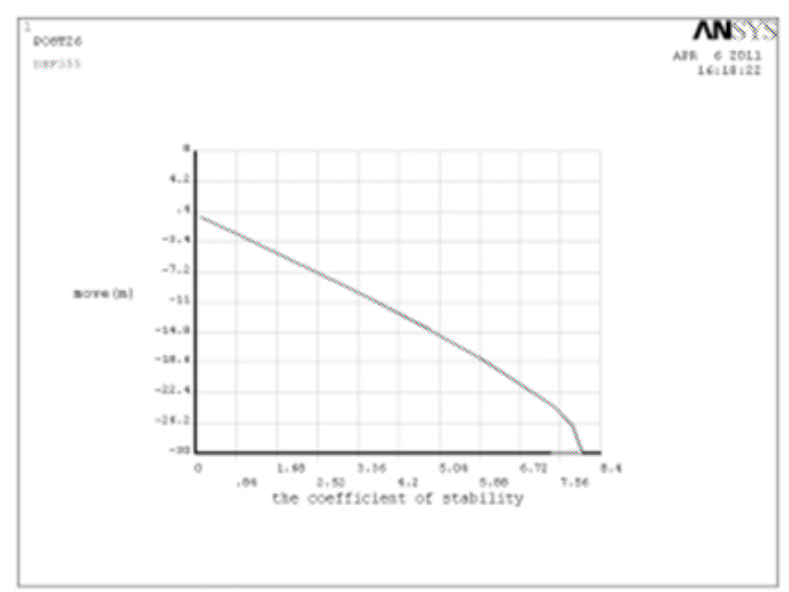

Figure 6. The factor of stability of semi-floating system

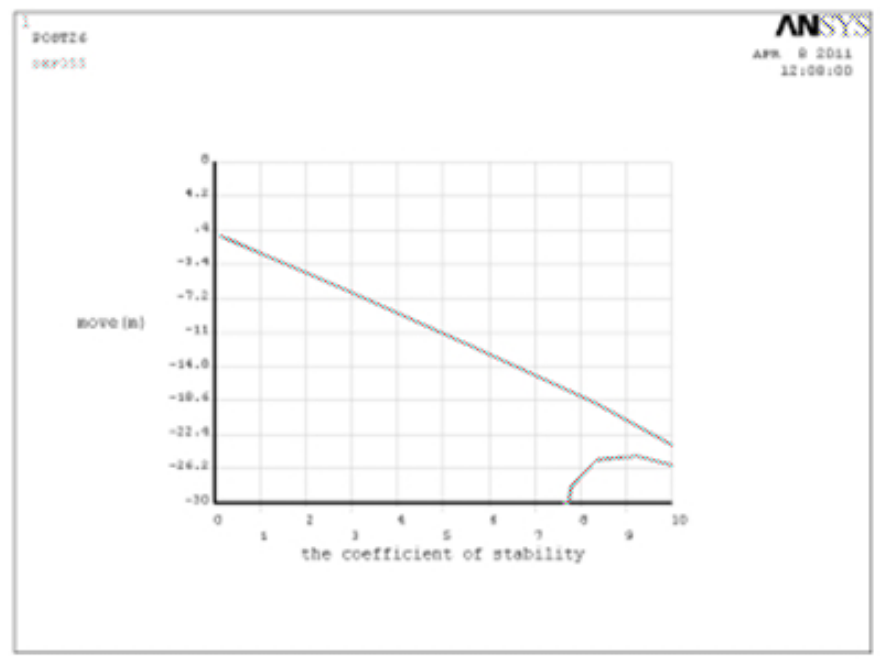

Figure 7. The factor of stabilityof consolidation system

(1) Floating system: The first-order linear buckling mode for the whole cable-stayed bridge is elegant along the longitudinal direction, first-order nonlinear instability modes is the middle deflection, there is little difference between linear elastic stability and nonlinear stability safety factor, and both are relatively small.

(2) Semi-floating system: The first-order linear buckling mode of cable-stayed bridge is local buckling of the main beam. The first-order nonlinear instability modes is the middle deflection, instability mode state has not changed, but the value of instability changes a lot relative to the floating state.

(3) Consolidation system: The first-order linear buckling mode of cable-stayed bridge is the middle deflection. The first-order nonlinear instability modes is the same as linear buckling mode, the value close to semi-floating state.

When the car load mid-span arrangement, there is the same conclusion.

\section{Conclusion}

(1) The structure buckling mode are all in the face under three different systems, when in floating system, the main beam prone to elegant along the longitudinal direction and stability safety factor is much smaller than the semi-floating system and consolidation systems, bridge stability is the worst.

(2) Structural stability in the consolidation system and semi-floating system is relatively better, but the construction of consolidation system relatively complex, and there is often stress concentration occurs in the tower, beams, piers consolidation location. Longitudinal elastic cord constraints has been optimized floating 
system, its implementation is simple, but the effect of improving the stability of large-span cable-stayed is obvious.

(3) Overall, cable-stayed bridge can select a different structural system, but for large-span cable-stayed bridge, the floating system plus longitudinal elastic cord restraint is an ideal one.

(4) In order to find the ideal system of large span cable-stayed bridge, we can study this issue depthly in the following two aspects:on the one hand, the length of longitudinal elastic cord and the range in the main beam, on the other hand, study the stress of key points in the tower,girders and piers.

\section{Acknowledgements}

This work was supported by the National Natural Science Foundation (51278512), The Youth Program Foundation of Chongqing Three Gorges University (12QN13) and Geological Disaster Prevention Research and Innovation Team of the Three Gorges Reservoir.

\section{References}

Choi, D. H., Yoo, H., Koh J. H., \& Nogami, K. (2007). Stability evaluation of steel cable-stayed-bridges by elastic and inelastic bucklinganalyses. Int $J$ Struct Stabil Dyn, 7(4), 669-691. http://dx.doi.org/10.1142/S0219455407002472

Eock, K. (2011). Nonlinear static and dynamic analysis of cable structures. Finite Elements in Analysis and Design, 47(3), 237-246. http://dx.doi.org/10.1016/j.finel.2010.10.005

Jiawu, M., \& Rucheng, X. (2006). Pe Summarized comparison study on global static stability of the Su-Tong cable-stayed bridge. Journal of Tongii University (Natural Science), 34(7), 869-873.

Peng, H., \& Zhao, G. H. (2011). The nonlinear static stability analysis of long-span cable-stayed bridge. Bridge and Tunnel Engineering, 74(2), 104-106.

Tang, E. K. C. (2010). Numerical simulation of a cable-stayed bridge response to blast loads, Part II: damage $\begin{array}{lllll}\text { prediction and } \text { FRP strengthening. } & \text { Eng. 32, }\end{array}$ http://dx.doi.org/10.1016/j.engstruct.2010.06.007

You, Q., He, P., Dong, X., Zhang, X., \& Wu, S. (2008). Sutong Bridge-the longest cable-stayed bridge in the $\begin{array}{lllll}\text { world. Structural } & \text { Engineering }\end{array}$ http://dx.doi.org/10.2749/101686608786455298

\section{Copyrights}

Copyright for this article is retained by the author(s), with first publication rights granted to the journal.

This is an open-access article distributed under the terms and conditions of the Creative Commons Attribution license (http://creativecommons.org/licenses/by/3.0/). 